\title{
Experimental and numerical study on effect of forming rate on AA5086 sheet formability
}

\author{
Cunsheng ZHANG ${ }^{1 *}$, Lionel LEOTOING ${ }^{2}$, Dominique GUINES ${ }^{2}$, Eric RAGNEAU ${ }^{2}$ \\ ${ }^{1}$ Shandong University, Key Laboratory of Liquid Structure and Heredity of \\ Materials (Ministry of Education) \\ 73 Jingshi Road, Jinan, Shandong Province, P.R.CHINA, 250061 \\ Email:zhangcs@sdu.edu.cn \\ Tel : +86(0)53181696577 Fax : +86(0)53188395811 \\ ${ }^{2}$ Université Européenne de Bretagne, France, INSA-LGCGM - EA 3913 \\ 20, avenue des Buttes de Coësmes 35043 RENNES Cédex
}

Tel : +33(0)2 $23238664 \quad F a x:+33(0) 223238726$

\begin{abstract}
With increasing application of aluminum alloys in automotive or aeronautic industries, it is necessary to characterize their deformation behaviors at large strains, high strain rates and elevated temperatures, which is relatively lacking today. The aim of this paper is to experimentally and numerically investigate the influence of forming rate and temperature on formability of an AA5086 sheet. Firstly, tensile tests are carried out at different temperatures $\left(20,230,290\right.$ and $\left.350^{\circ} \mathrm{C}\right)$ and at different forming rates $(10,750$ and $1000 \mathrm{~mm} / \mathrm{s}$ ). A technique of digital image correlation (DIC) associated with a high-speed camera is applied to evaluate the surface strains and a complete procedure is built to detect the onset of localized necking during the experiments. The influences of initial testing temperature and forming rate on the sheet formability are analyzed. Then in order to numerically determine the formability of this sheet, a form of Voce's constitutive law taking
\end{abstract}


into account the temperature and strain rate is proposed. An inverse analysis is carried out to identify the material parameters of the law for the tested aluminum alloy. Finally, with the above identified law, tensile tests are simulated. The experimental and numerical results show that the testing temperature and forming rate have a great influence on sheet formability. At high forming rates, the sheet formability of AA5086 is lowered up to a certain temperature, above this temperature, the formability is greatly enhanced. Furthermore, the agreement between experimental and numerical results indicates that the proposed constitutive law and the identified material parameters can be appropriate to model the sensitivity of AA5086 sheet towards strain rate and temperature.

Key words: Forming Limit Diagrams (FLDs); Dynamic tensile test;

Digital Image Correlation (DIC); Inverse analysis

\section{Introduction}

Sheet metal forming is a very commonly used method for producing various components in automotive or aeronautic industries. Especially with the innovative techniques, such as hydroforming and incremental forming, the manufacture of complex parts with low cost can be realized. However, in sheet metal forming operations, the sheet can be deformed only to a certain limit. This limit is usually imposed by the onset of localized necking, which may lead to early failure. The ability of sheet metal to deform into desired shape without local necking or fracture is defined as its formability. Formability depends on many factors like material properties (e.g. strain hardening coefficient, strain rate sensitivity, anisotropy ratio) or process parameters 
(e.g. strain rate, temperature) [19]. Thus, understanding and characterizing the formability of metal sheets are crucial for controlling final product quality and then the success of the sheet forming operation, especially with the increasing use of aluminum alloys that exhibit low formability compared with typical mild steels $[13,7]$.

One important technique to evaluate the formability of sheet metals is the use of forming limit diagrams (FLDs) developed by Keeler and Backofen in the 1960s [9]. For sheet metal forming, FLDs are realistic and efficient diagnostic tools for evaluating formability. In addition, due to the improvement of production rates, strain rates in sheet forming processes can be located in the range of intermediate strain rates $\left(10^{-2}\right.$ to $\left.500 \mathrm{~s}^{-1}\right)$. Nevertheless, the mechanical behavior of materials at intermediate and high strain rates can be considerably different from that observed with quasi-static loading because of the strain-rate sensitivity of the material and propagation of stress waves [21]. Further, strain-rate sensitivity has been identified as an important factor determining formability of sheet metal and can alter substantially the level and the shape of FLCs. Of particular interest here is the influence of strain rate on the forming capacity of metals during the forming process. A review of currently available literature shows that relatively little attention has been paid to models for FLDs taking strain rate into account.

Different analytical models have been developed that focus either on diffuse or localized necking. These models not only help to understand the necking phenomenon but they represent also useful tools to successfully and rapidly predict the formability of sheet metals in industrial practice. The strain rate sensitivity has been studied mainly through the classical M-K 
model. One of the first studies taking into account this effect was proposed by [8]. Considering a von Mises' yield function, the effect of strain rate sensitivity have been evaluated. Afterwards, anisotropy of sheet metals was introduced in this classical model by using different yield function, like the Hill's criterion [1] or the Logan's and Hosford's criterion [6]. In these analytical models, the strain hardening behavior and the strain rate sensitivity of materials are generally represented by simplistic power laws. For some materials, especially for aluminium alloys, this formulation is not well adapted to model the strain rate effects and then the onset of local necking [3]. Moreover, it has been shown that these simplistic laws only permit the study of the influence of the strain rate sensitivity index but not the influence of the value of the strain rate and temperature [23].

Experimentally, the Nakazima [14] and Marciniak tests [12] are widely used to study sheet formability at quasi-static loading. Under dynamic conditions, it is relatively difficult to adapt these conventional tests. Percy [17] analyzed the influence of strain rate on FLDs by explosive forming and concluded that FLDs level was dependent on the strain state and forming rates. Broomhead et al. [2] performed bulge forming over a range of strain rates from $10^{-3}$ to $70 s^{-1}$ and concluded that the position of FLDs for biaxial tensile conditions was lowered with increasing strain rate. The effects of temperature and forming speed on FLCs of an Al-Mg alloy (5083-O) sheet have been investigated by Naka and Yoshida [15] for different speeds $(0.2-200 \mathrm{~mm} / \mathrm{min})$ and at temperatures of $20-180{ }^{\circ} \mathrm{C}$. Experimental results showed that the level of FLC increases with increasing temperature and decreasing forming speed. By deep drawing of rectangular parts at a certain strain rate $\left(1 s^{-1}\right)$ con- 
ducted by Li and Ghosh [10], FLCs under warm forming conditions (250, 300 and $350{ }^{\circ} \mathrm{C}$ ) were also determined for three different aluminum alloys (AA5754, AA5182 and AA6111-T4). They all exhibit a significant improvement in their formability with increasing temperature. Moreover, Ghosh [5] has pointed out that warm formability drops with increasing forming speed. However, no correlations have been presented between these experimental results and those of numerical or analytical predictive model of FLCs.

With the increasing application of computational techniques, numerical predictions of FLDs have become more attractive and the finite element method (FEM) has been selected to analyze the necking process ([18], [22]). In these models, the choice of an appropriate failure criterion is a key point for the determination of accurate FLCs [20]. Moreover, it is found that the hardening law implemented in finite element codes influence greatly the level and shape of FLCs [24]. Therefore, an appropriate viscoplastic constitutive model and a reliable identification of its parameters are primordial for the formulation of an efficient formability predictive tool.

By use of the uniaxial tensile test, one point of the FLC can be obtained. From the previous analytical studies of present authors, this point seems to be very sensitive to the strain rate sensitivity of the material [24]. Moreover, the uniaxial tensile test is well controlled under dynamic loading. Hence, a tensile test performed at various forming rates can firstly be used to analyze the sensitivity of forming behavior to strain rate.

Therefore, it is necessary to establish a rigorous procedure and carry out more experimental investigations about forming behavior in a large range of strain rates. One of the aims of this work is to propose an experimental 
procedure to characterize the effect of initial testing temperature and forming rate on sheet formability. Firstly, a dynamic tensile test is conducted for an AA5086 sheet at different temperatures (20, 230, 290 and $350{ }^{\circ} \mathrm{C}$ ) and different forming rates $(10,750$ and $1000 \mathrm{~mm} / \mathrm{s})$. A technique of digital image correlation associated with a high-speed camera is used to evaluate the strains on the specimen surface and a complete procedure is built to detect the onset of localized necking during the experiments. Then a form of Voce's constitutive law is proposed and an inverse analysis is applied to identify the material parameters of this aluminum sheet for the different investigated conditions. Finally, with the above identified laws, the dynamic tensile test is simulated with ABAQUS and the comparison of experimental and numerical results is given.

\section{Experimental procedure and results}

The dynamic tensile tests are carried out on a computer-controlled servo-hydraulic testing machine. The actuator accelerates upward with the crosshead to achieve a desired velocity before loading the test sample and this velocity can be considered to remain constant during the test. To augment the sensitivity of this alloy to strain rate, tensile tests are conducted at different temperatures $\left(20,230,290\right.$ and $\left.350{ }^{\circ} \mathrm{C}\right)$. The displacements are controlled at constant rate and increased from 10 to $1000 \mathrm{~mm} / \mathrm{s}$, prescribing average strain rates of order $10^{-1}$ to $10^{2} s^{-1}$ in the defined specimen.

\subsection{Experimental device}

In this work, a tensile specimen is designed with a notch which results in necking initiation in the central region of the specimen and then facilitates 
the capture of consecutive frames. The geometry and dimensions of the specimens are shown in Fig. 1. The thickness of the AA5086 sheet is 2.0 $\mathrm{mm}$.

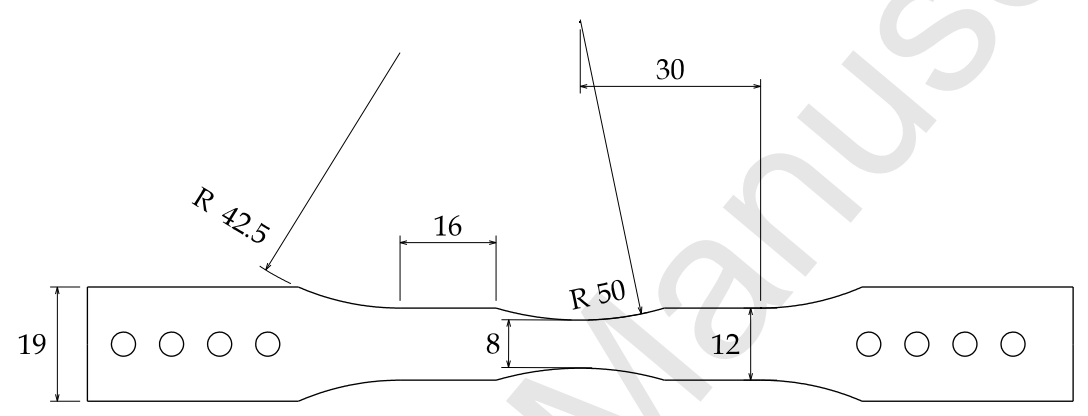

Figure 1: Geometry and dimensions of the notched specimen (lengths in mm).

To satisfy the requirement that the longitudinal axis of the test specimen coincides with tensile direction of the testing machine, a recently designed grip system is used during the experiments, as shown in Fig. 2. The heels are used to clamp the test specimen at its two ends. They are mounted on the testing machine with the upper and lower grips. More importantly, under dynamic conditions, the device allows a predetermined run where the sample is accelerated to a desired test velocity. 


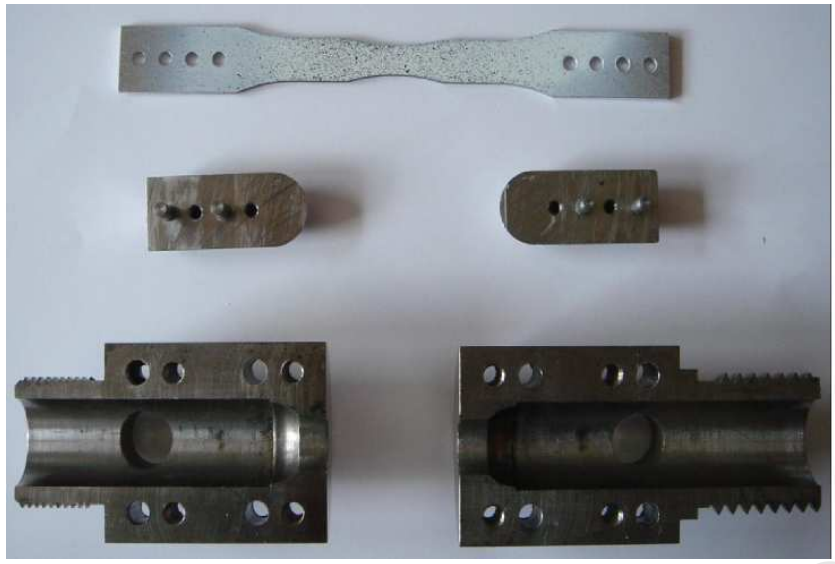

(a) Specimen painted

(b) Heels

(c) Grips

Figure 2: Grip system used in the dynamic tensile test.

Here, to capture the consecutive frames during the experiments, a highspeed camera is used (FASTCAM ultima APX-RS digital CMOS camera) associated with a macro lens, which is ideally suited for high magnification close range applications. Additional light is required to illuminate the sample during testing. A high frequency induction heating system is applied to heat the specimen. Once the specimen is heated to the target temperature, tensile test is performed. The camera and the load acquisition are triggered just before the test is started to capture a picture of undeformed specimen.

Due to inherent hardware limitations of the camera, the higher the resolution, the lower the possible sample rate. In our experiments, the tests are performed at different crosshead speeds. Therefore, in order to get a good representation of the central zone deformation of the specimen, the testing speed and view resolution should be optimized for each speed, the chosen balance is listed in Table 1 . 
Table 1: Camera settings

\begin{tabular}{ccc}
\hline Testing speed $(\mathrm{mm} / \mathrm{s})$ & Camera resolution (Pixels) & Camera speed (images $/ \mathrm{s})$ \\
\hline 10 & $512 \times 758$ & 1500 \\
750 & $256 \times 656$ & 12000 \\
1000 & $128 \times 352$ & 18000 \\
\hline
\end{tabular}

\subsection{Strain evaluation and determination of the onset of localized necking}

Digital image correlation (DIC) is a technique for non-contact strain measurement and surface profilometry, which is nowadays widely used for forming analysis of metal sheets as well as the determination of material properties. For strain measurement using the DIC technique, the sample is prepared by the application of a random dot pattern to its surface. In this work, to avoid burning paints at elevated temperature, shotblasting treatment is applied to replace white paint and produce white basecoat on specimen surface. The zone of interest on the specimen surface is divided into small subsets (small grid in Fig. 3(a)). Then the system tries to match the grey level distribution of these subsets on the deformed images. This matching operation is carried out throughout a displacement transformation applied to the subsets.

To perform correlation analysis in this work, the commercial digital imaging program CORRELA2006 is employed. The DIC program calculates the large strains in the plane of the test $\left(\varepsilon_{x x}, \varepsilon_{y y}\right.$ and $\left.\varepsilon_{x y}\right)$ and the principal strains $\left(\varepsilon_{11}\right.$ and $\left.\varepsilon_{22}\right)$ for each subset at different times. Then the equivalent plastic strain can be computed for each subset. Hereafter, we use the uniaxial tensile test performed under $10 \mathrm{~mm} / \mathrm{s}$ at room temperature to analyze the deformation process, as an illustrative example. 
Differently from a specimen with constant cross-section, in this notched specimen, the strain in the zone of interest (grided zone in Fig. 3(a)) is nonhomogeneous during the test. Hence, in order to minimize the randomicity of the experimental results and find a representative procedure for analyzing the necking progress, the equivalent plastic strains in sections are obtained by calculating the average strains of grids in the same rows (in the $y$-direction on Fig. 3(a)). To study the evolution of localized necking throughout tests, Fig. 3(b) displays the time-sequence of these equivalent plastic strain profiles along the axis $x$ with a regular time step. 


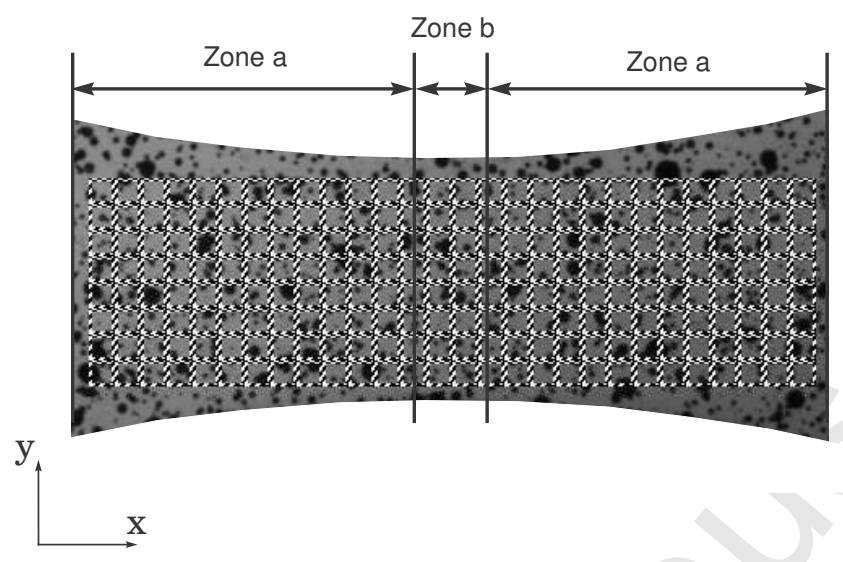

(a) Grid zone of interest on specimen surface

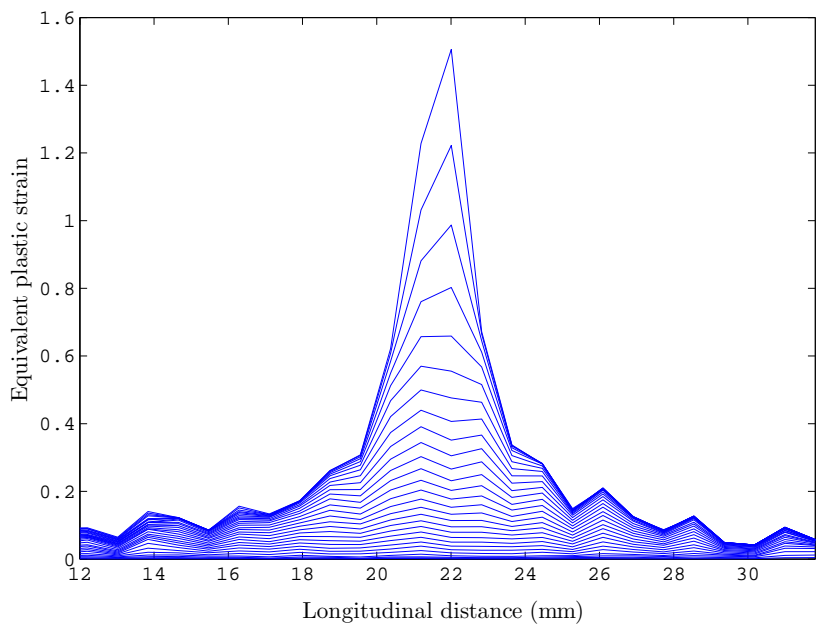

(b) Evolution of equivalent plastic strain profile at different instants of time.

Figure 3: Experimental analysis and determination of onset of localized necking.

From the figure 3(b), it is observed that at early stage of the test, a quasi-homogeneous deformation is distributed along the axis $x$. The subsequent development of deformation is concentrated to the central part of the 
specimen notch, and the plastic strain is localized to a smaller and smaller region. After a certain moment, the equivalent plastic strain in the localized zone (Zone $b$ ) rises extremely rapidly while the non-localized zone (Zone $a$ ) shows a saturation in the equivalent plastic strain. The necking ultimately ends with the onset of a rupture in the localized zone. The growth of this localized necking can also be illustrated in Fig. 4, which plots the ratio of average equivalent plastic strain increments in the localized (Zone $b$ ) and nonlocalized zones (Zone $a$ ) throughout time. One can observe that this ratio keeps relatively stable (close to 1) until about $0.52 \mathrm{~s}$. After this moment, the ratio increases suddenly and localized necking, i.e. plastic instability, begins to occur. In this work, a failure criterion widely used for the M-K model is chosen: when this ratio reaches 7 , localized necking is assumed to occur. At this moment, the principal strains $(-0.067,0.30)$ in Zone $b$ are retained as limit strains. As illustrated in Fig. 4, the equivalent plastic strain increment ratio changes so suddenly, hence the critical value in the failure criterion has no great influence on the determination of the limit strains. Therefore, the value of 7 is reasonable as a failure criterion for predicting the onset of the localized necking. 


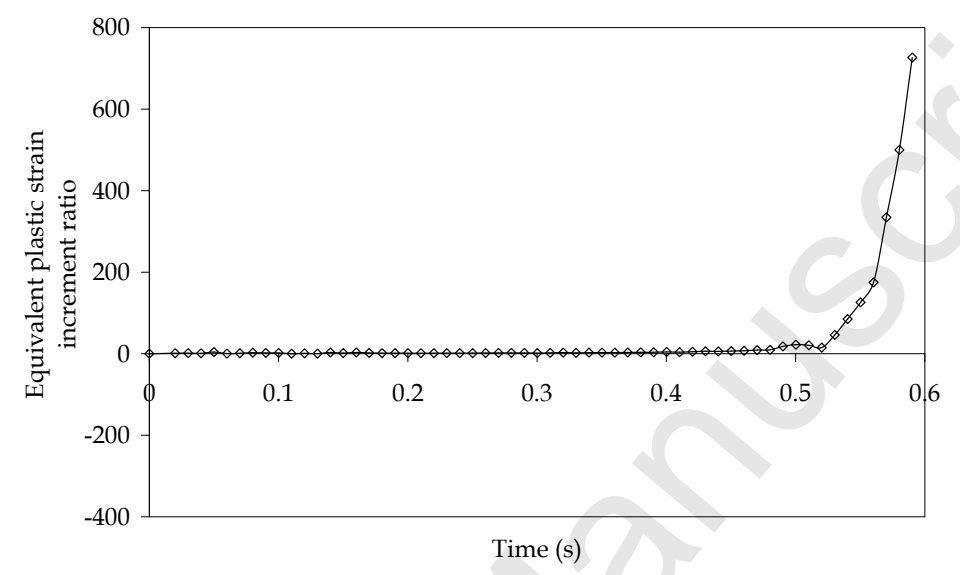

Figure 4: Variation of equivalent plastic strain increment ratio in the localized and nonlocalized zones.

\subsection{Experimental results}

Figure 5 represents the effect of temperature on the evolution of the forcedisplacement curves measured during the plastic stage of the specimen deformation. For a quasi-static test speed $(10 \mathrm{~mm} / \mathrm{s})$, a thermal softening is clearly observed on these curves, when the test temperature increases from $20^{\circ} \mathrm{C}$ to $350^{\circ} \mathrm{C}$ the maximum tensile force is decreased by half. On Figure 6 , the temperature is fixed at $350^{\circ} \mathrm{C}$ and the evolutions of the force-displacement curves are plotted for three different forming speeds. In order to properly analyze the mechanical behavior of the material under dynamic conditions $(750 \mathrm{~mm} / \mathrm{s}$ and $1000 \mathrm{~mm} / \mathrm{s})$, the oscillations due to impact-induced stress wave travelling through the specimen have been filtered out. An increasing load level is observed with increasing forming speed, the magnitude of this 
effect depends on the level of the test temperature. As a result, for high temperatures, the effect of strain rate on the material behavior should be taken into account for accurate rheological predictions.

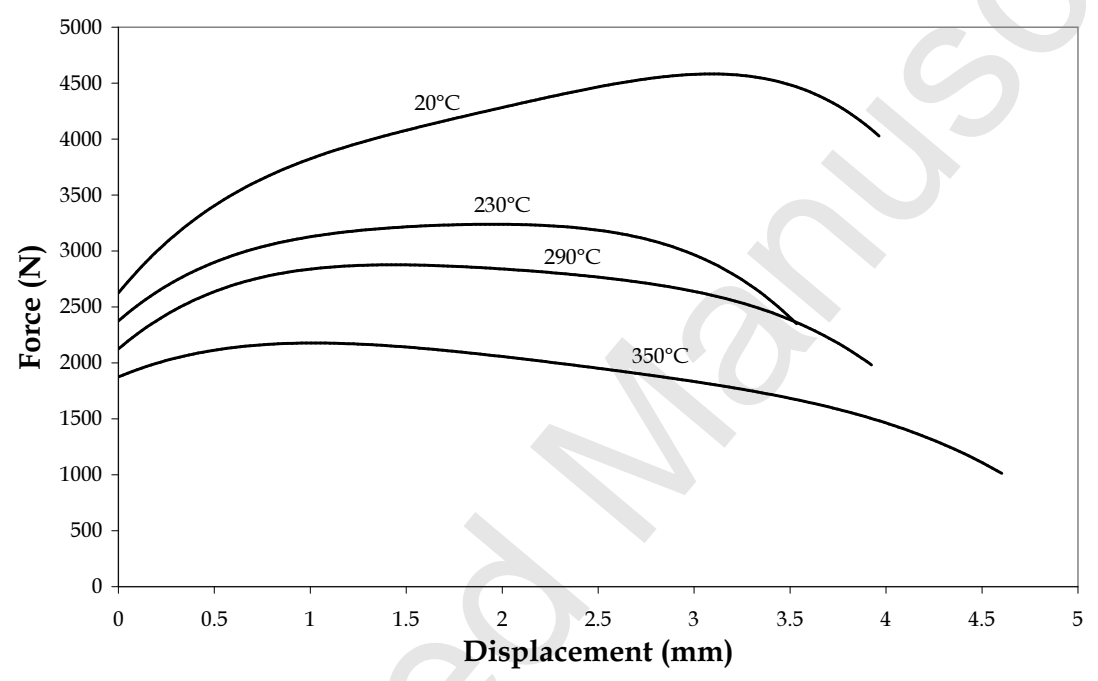

Figure 5: Influence of temperature on force-displacement evolutions at $10 \mathrm{~mm} / \mathrm{s}$ and for the plastic stage. 


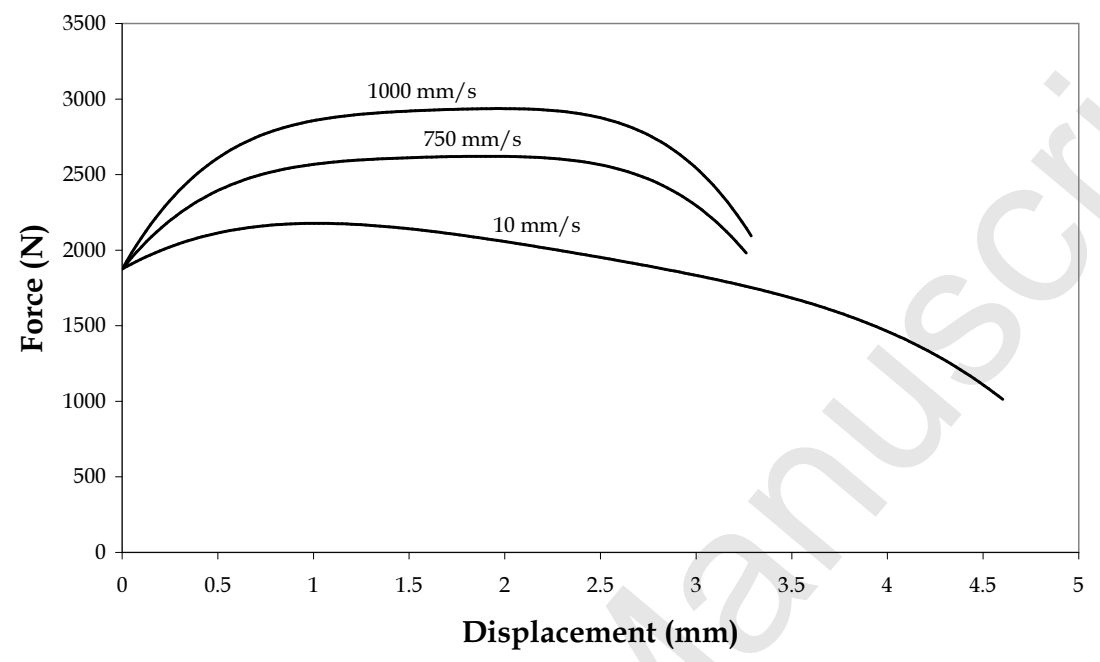

Figure 6: Influence of tensile speed on force-displacement evolutions at $350^{\circ} \mathrm{C}$ and for the plastic stage.

Figure 7 shows the evolution of the major strains in terms of the temperature $\left(20,230,290\right.$ and $\left.350{ }^{\circ} \mathrm{C}\right)$ and testing speeds (10,750 and 1000 $\mathrm{mm} / \mathrm{s}$ ). The minor strains are not represented here but the same tendencies are observed, due to the constant strain path for all the specimens. Three specimens are tested for each condition, and the different curves are plotted by using the average major strain for each condition. In all cases, the scatter from test to test is relatively low.

As the figure 7 demonstrates, forming limit becomes considerably higher with low forming rate $(10 \mathrm{~mm} / \mathrm{s})$ and elevated temperature. At room temperature, limit strains are not so sensitive to forming rate. By comparison, at $290{ }^{\circ} \mathrm{C}$, with the forming rate from 10 to $750 \mathrm{~mm} / \mathrm{s}$, a $69 \%$ reduction in 


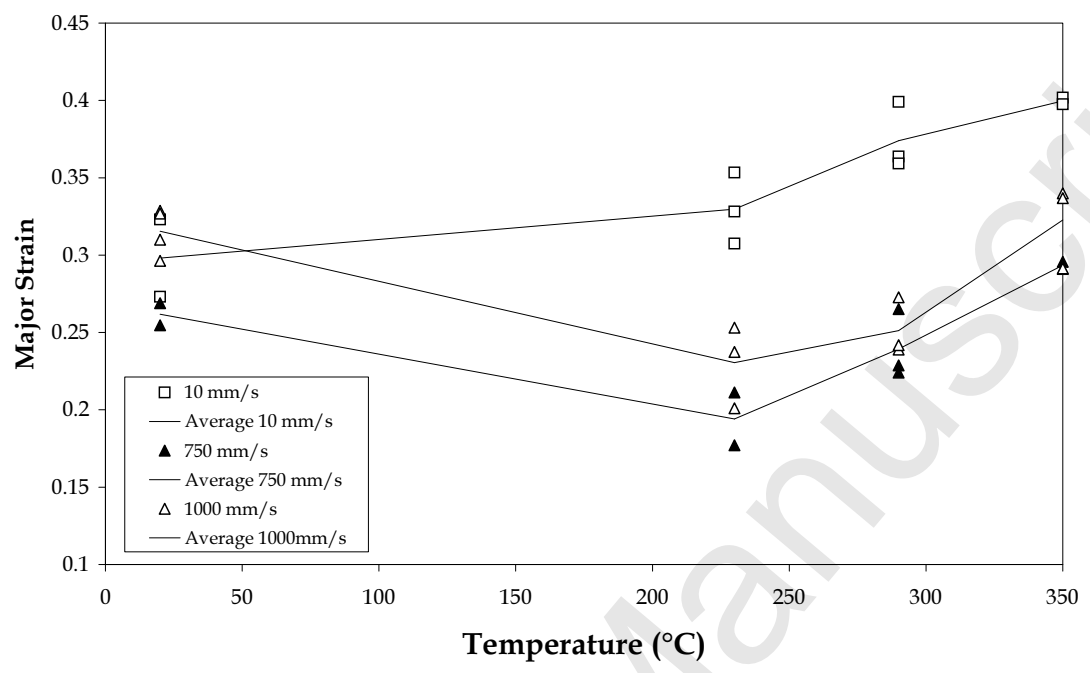

Figure 7: Limit strains under different forming rates and temperatures.

major strain can be observed, while at $350{ }^{\circ} \mathrm{C}$, a relative decrease of $51 \%$ is exhibited. It is true that there is no significant differences between strains at 750 and $1000 \mathrm{~mm} / \mathrm{s}$, because these two forming rates are relatively close. In conclusion, at elevated temperature, forming rate plays a prominent role in determining sheet formability. At low forming rate $(10 \mathrm{~mm} / \mathrm{s})$, the testing temperature always plays a positive effect on sheet formability. It may be concluded that at $350{ }^{\circ} \mathrm{C}$, an increasing forming rate compensates the positive effect of temperature on the formability, and this leads to an insignificant effect of temperature on the formability for this range of rate (major strain remains close to $30 \%$ ). At $230^{\circ} \mathrm{C}$, the compensating effect of forming rate is more pronounced, consequently, we observe the lowest major strains at this temperature for the two high speeds tested. Differently from the conclusion 
in $[10,15,5]$, with increasing temperature, there does not exhibit a single trend in major strains at different forming rates. The aim of the following parts is to find numerically this notable evolution thanks to an appropriate constitutive law.

\section{Identification of material's constitutive laws}

Based on the above tensile test with a notched specimen, it is difficult to identify the material's flow behavior with conventional analytical methods due to the irregular specimen cross-section. Nowadays, the inverse methods are intensively used to adjust the material parameters for more and more complex constitutive laws or irregular specimen geometry. The basic concept of an inverse analysis for parameter identification is to find out a set of unknown material parameters in constitutive equation thanks to a Finite Element simulation of the test.

\subsection{Constitutive law}

At high temperatures, the mechanical behavior of aluminium alloys results from a balance between work-hardening and thermal softening. This behavior can be represented by the use of a Voce's hardening law ([11],[3]) (Eq. 1)

$$
\bar{\sigma}=\sigma_{0}+C_{1} \sqrt{1-e^{-n(T) \bar{\varepsilon}}} e^{\left(\frac{C_{4}}{T}\right) \dot{\bar{\varepsilon}}^{m(T)}}
$$

where $\bar{\sigma}$ and $\bar{\varepsilon}$ are the equivalent plastic stress and strain, respectively, and $\sigma_{0}$ the yield strength. In order to model the influence of temperature on the wide range tested (from 20 to $350{ }^{\circ} \mathrm{C}$ ), an exponential form of the strain hardening index $n(T)$ is proposed in this work : 


$$
n(T)=C_{2} e^{\left(C_{3} T\right)}
$$

For the strain rate sensitivity index $m(T)$, a linear evolution with temperature seems to be appropriate :

$$
m(T)=C_{5}+C_{6} T
$$

The coefficients $C_{i}(i=1 . .6)$ are constants, they will be identified through the inverse analysis procedure. Due to the sheet plane quasi-isotropy of AA5086, a von Mises's yield function is used in the FE model.

\subsection{Results}

The identification procedure (OPTPAR) used in the present work, developed by Gavrus [4], is based on an iterative Gauss-Newton's algorithm, using numerical computation of the first order derivatives of the cost function with respect to the parameters to be identified. The identification of the constitutive parameters is performed with a FE simulation of the tensile test using the ABAQUS software until the minimum of the cost function is reached. The FE model for inverse analysis is shown in Fig. 8, which is meshed with triangle elements. By means of the user-defined FORTRAN subroutine UHARD, the constitutive law (Eq. 1) can be implemented into the finite element code.

In this work, we suppose that the value of the yield strength depends only on temperature but not on strain rate level, which is commonly verified for aluminum alloys [16]. The yield strengths and the identified constitutive parameters $C_{i}$ are given in table 2 . 


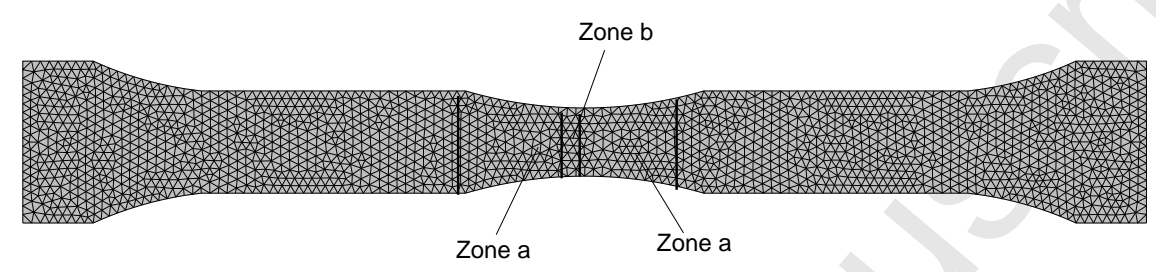

Figure 8: FE model used for inverse analysis.

The comparison between experimental and calculated loads versus displacement at $10 \mathrm{~mm} / \mathrm{s}$ is illustrated in Fig.9. There is much discrepancy between experimental and identified curves of load vs. displacement for higher temperatures, but these curves curves are obtained under the same low forming rate $(10 \mathrm{~mm} / \mathrm{s})$, therefore, the influence of strain rate on this discrepancy is probably less. The agreement between the experimental curves and the ones identified by inverse analysis is not perfect but the Voce's constitutive law and the identified parameters permit to well model the global effect of temperature and strain rate on the behavior of this aluminium alloy, on the wide range of tested temperatures and forming rates. Considering self-heating, thermal radiation and conductivity, not presented in this work, should improve the identification of the parameters. 
Table 2: Yield strengths and constitutive parameter values.

\begin{tabular}{|c|c|c|c|c|}
\hline & $20^{\circ} \mathrm{C}$ & $230^{\circ} \mathrm{C}$ & $290^{\circ} \mathrm{C}$ & $350^{\circ} \mathrm{C}$ \\
\hline$\sigma_{0}(\mathrm{MPa})$ & 162.7 & 147.2 & 131.7 & 116.2 \\
\hline$C_{1}(\mathrm{MPa})$ & \multicolumn{4}{|c|}{27.41} \\
\hline$C_{2}$ & \multicolumn{4}{|c|}{1.76} \\
\hline$C_{3}\left(K^{-1}\right)$ & \multicolumn{4}{|c|}{$2.0810^{-3}$} \\
\hline$C_{4}(\mathrm{~K})$ & \multicolumn{4}{|c|}{606.20} \\
\hline$C_{5}$ & \multicolumn{4}{|c|}{$-110^{-6}$} \\
\hline$C_{6}\left(K^{-1}\right)$ & \multicolumn{4}{|c|}{$1.5410^{-4}$} \\
\hline
\end{tabular}

\section{Numerical study and discussion}

With the above identified constitutive laws, the tensile test is simulated at different temperatures and forming speeds. The onset of localized necking is analyzed with the identical procedure to experiments. Figure 10 shows the comparison of evolution of the limit major strains in terms of the temperature $\left(20,230,290\right.$ and $350{ }^{\circ} \mathrm{C}$ ) and high tensile speeds (750 and 1000 $\mathrm{mm} / \mathrm{s}$ ) by experimental and numerical methods. From this figure, one can observe the same phenomenon on numerical and experimental results, i.e. the negative effect of strain rate on formability up to $230{ }^{\circ} \mathrm{C}$. The experimental limit major strains are slightly lower than numerical ones (except for $350{ }^{\circ} \mathrm{C}$ ). Especially at $230{ }^{\circ} \mathrm{C}$, a relative difference of $20 \%$ in major strains exists. One reason for this divergence might results from the discrepancies observed between experimental load-displacement curves and the identified ones. Even So, the compensating effect of temperature and forming rate is clearly observed and the same tendencies of major strain versus temperature 


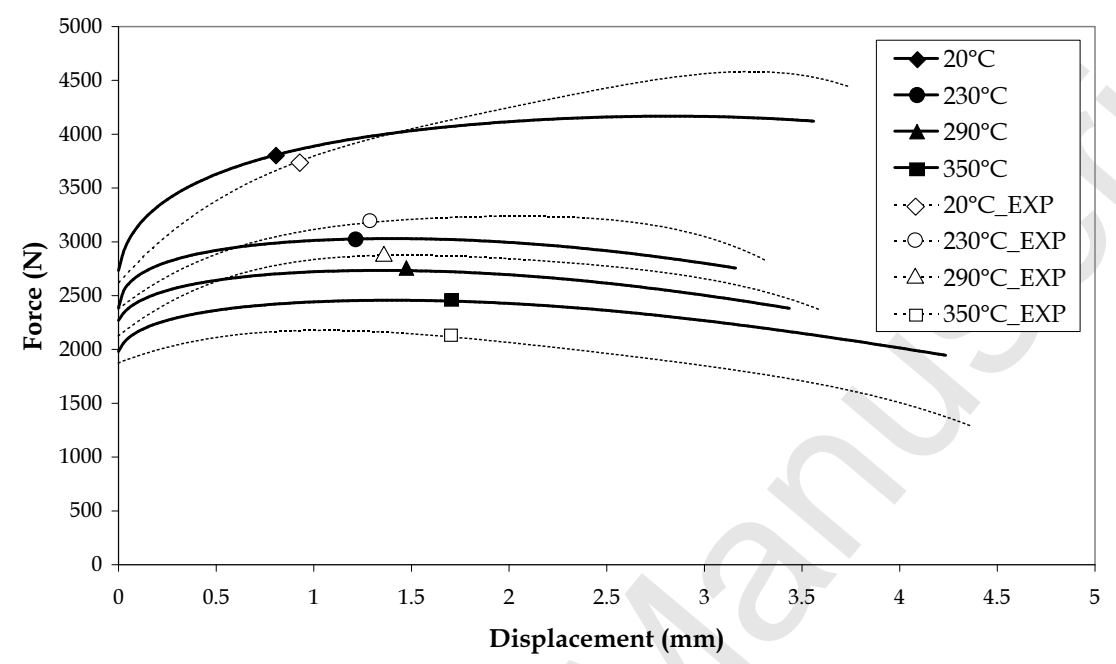

Figure 9: Experimental and identified curves of load versus displacement at 10mm/s

and forming rate are found. For 750 and $1000 \mathrm{~mm} / \mathrm{s}$, the sheet formability of AA5086 is lowered up to a certain temperature (between $200^{\circ} \mathrm{C}$ and $250^{\circ} \mathrm{C}$ ), above this temperature, the formability is enhanced by a stronger thermal softening. It seems to be rather difficult to give the complete and exact explanation about the decrease of sheet formability in the range 200 to $250^{\circ} \mathrm{C}$. Very few studies exist in the literature. Naka et al. [15] explain that the decrease of formability with stain rate is due to a lower value of the strain rate sensitivity index $\mathrm{m}$ in this range of temperature. Nevertheless, their approach is based on a very simplistic constitutive equation which can not reproduce the material behaviour of an aluminum alloy in a wide range of temperature and strain rate. It exists a competition between the mechanism of thermal softening and the evolution of the strain rate index 
with temperature, then considering a more elaborate constitutive law which could take into account the different coupling effects between temperature and strain rate is essential. This agreement between numerical and experimental results in turn indicates that the proposed constitutive law seems to be appropriate to model the thermal softening and work-hardening effect on mechanical behaviour of an AA5086 sheet.

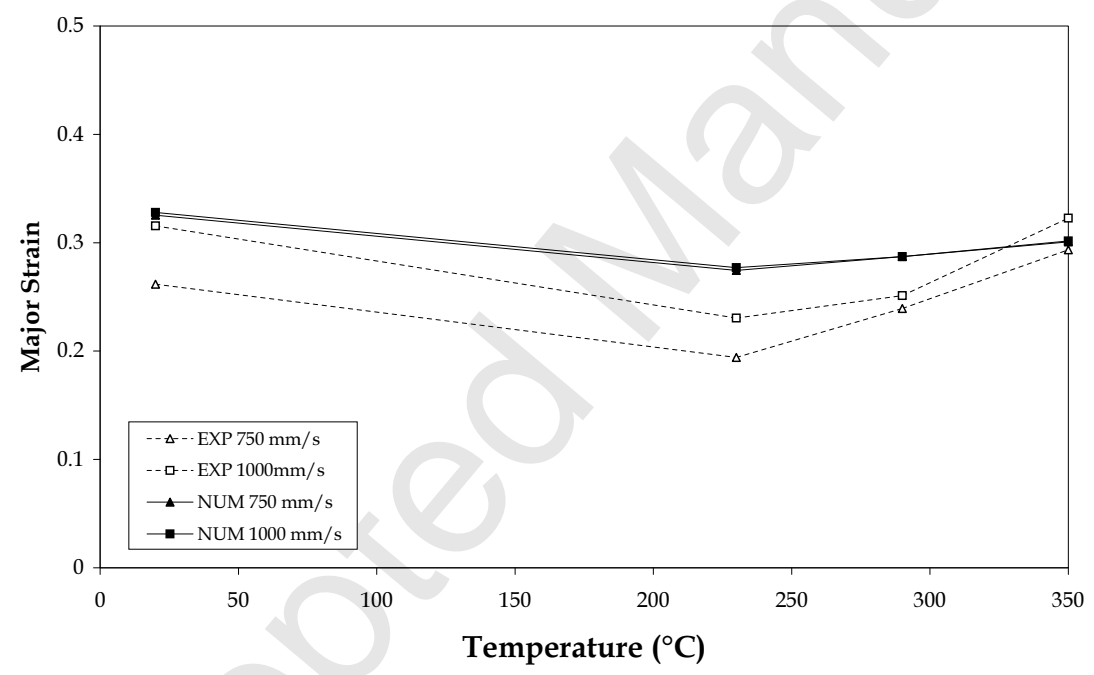

Figure 10: Experimental and numerical limit strains under different forming speeds and temperatures.

\section{Conclusions}

This paper investigates experimentally and numerically the effect of forming rate and temperature on sheet formability of an AA5086 sheet. By carrying out a dynamic experimental tensile test and its associated FE model, 
the following conclusions can be drawn.

- The technique of digital image correlation associated with a high-speed camera has been successfully applied to evaluate the strains at high forming rates and at high temperatures. With the time-sequence of equivalent plastic strain profiles along the specimen's longitudinal axis, a complete procedure is built to detect the onset of localized necking during the experiments.

- To describe the forming behavior of this AA5086 sheet, a form of Voce's hardening law taking into account the temperature and strain rate is proposed. The inverse method is used to identify the material parameters for this law. The agreement between experimental and numerical results indicates that this constitutive law and identified material parameters can model the high temperature deformation behavior of the sheet.

- The comparison of experimental and numerical results shows that for high strain rates (around $10^{2} s^{-1}$ ), the sheet formability seems to be lowered up to a certain temperature (between $200^{\circ} \mathrm{C}$ and $250^{\circ} \mathrm{C}$ ), above this temperature, the formability is enhanced and the negative effect of strain rate on formability is compensated.

\section{References}

[1] A. Barata da Rocha, F. Barlat, and J.M. Jalinier. Prediction of the forming limit diagrams of anisotropic sheets in linear and non-linear loading. Materials Science and Engineering, 68:151-164, 1984-1985. 
[2] P. Broomhead and R.J. Grieve. The effect of strain rate on the strain to fracture of a sheet steel under biaxial tensile stress conditions. Journal of Engineering Materials and Technology, 104:102-106, 1982.

[3] S. Diot, D. Guines, A. Gavrus, and E. Ragneau. Forming process of a 5083 aluminium alloy. constitutive model covering a large range of temperature. International Journal of Forming Processes, 9:167-188, 2006.

[4] A. Gavrus. Identification automatique des paramètres rhéologiques par analyse inverse. PhD thesis, Ecole Nationale Supérieure des Mines de Paris, France, 1996.

[5] A.K. Ghosh and A. Arbor. Sheet metal stamping die design for warm forming. Patent, University of Michigan, 2003.

[6] A. Graf and W. Hosford. Calculations of forming limit diagrams. Metallurgical Transactions A, 21A:87-93, 1990.

[7] A. Heinz, A. Haszler, C. Keidel, S. Moldenhauer, R. Benedictus, and W.S. Miller. Recent development in aluminum alloys for aerospace applications. Materials Science and Engineering A, 280:102-107, 2000.

[8] J.W. Hutchinson, K.W. Neale, and A. Needleman. Mechanics of sheet metal forming, pages 269-285. New York/London, Plenum Press, 1978.

[9] S.P. Keeler and W.A. Backofen. Plastic instability and fracture in sheets stretched over rigid punches. Trans. ASM, 56:25-48, 1963. 
[10] D. Li and A.K. Ghosh. Biaxial warm forming behavior of aluminum sheet alloys. Journal of Materials Processing Technology, 145:281-293, 2004 .

[11] P. Lukac. Characterisation and modelling of the plastic behaviour of aluminium alloys. Aluminium Alloys - Materials Science Forum, 217222:71-82, 1996 .

[12] Z. Marciniak, K. Kuczynski, and T. Pokora. Influence of the plastic properties of the material on the forming limit diagram for sheet metal tension. International Journal of Mechanical Sciences, 15:789-805, 1973.

[13] W.S. Miller, L. Zhuang, J. Bottema, A.J. Wittebrood, P. De Smet, A. Haszler, and A. Vieregge. Recent development in aluminium alloys for the automotive industry. Materials Science and Engineering A, 280:3749, 2000.

[14] K. Nakazima, T. Kikuma, and K. Asuka. Study on the formability of steel sheet. Technical report, Yawata, 1971.

[15] T. Naka, G. Torikai, R. Hino, and F. Yoshida. The effects of temperature and forming speed on the forming limit diagram for type 5083 aluminummagnesium alloy sheet. Journal of Materials Processing Technology, 113:648-653, 2001.

[16] K.O. Pedersen, H.J. Roven, O.G. Lademo, and O.S. Hopperstad. Strength and ductility of aluminium alloy AA7030. Microstructure and Processing, 473:281-289, 2008. 
[17] J.H. Percy. The effect of strain rate on the FLD for sheet metal. Annals of the CIRP, 29:151-152, 1980.

[18] A. Petek, T. Pepelnjak, and K. Kuzman. An improved method for determining forming limit diagram in the digital enviroment. Journal of Mechanical Engineering, 51:330-345, 2005.

[19] M. Seth. High velocity formability and factors affecting it. PhD thesis, The Ohio State University, 2006.

[20] Q. Situ, M. Jain, and M. Bruhis. A suitable criterion for precise determination of incipient necking in sheet materials. Materials Science Forum, 519-521:111-116, 2006.

[21] V. Tarigopula, O.S. Hopperstad, M. Langseth, A.H. Clausen, and F. Hild. A study of localisation in dual-phase high-strength steels under dynamic loading using digital image correlation and FE analysis. International Journal of Solids and Structures, 45:601-619, 2008.

[22] W. Volk. New experimental and numerical approach in the evaluation of the FLD with the FE-method. In Proceedings of the FLC-Zurich 06, Zurich, Switzerland, 2006.

[23] C.S. Zhang, L. Leotoing, D. Guines, and E. Ragneau. Theoretical and numerical study of strain rate influence on AA5083 formability. Journal of Materials Processing Technology, 209:3849-3858, 2009.

[24] C.S. Zhang. Investigations on the effect of strain rate sensitivity on formability of aluminium alloy sheets. PhD thesis, INSA de Rennes, France, 92008. 